\title{
A prion disease of cervids: Chronic wasting disease
}

\author{
Christina J. SIGURDSON* \\ Department of Pathology, University of California, San Diego, 9500 Gilman Dr., La Jolla, \\ CA 92093-0612, USA
}

(Received 1 November 2007; accepted 31 March 2008)

\begin{abstract}
Chronic wasting disease (CWD) is a prion disease of deer, elk, and moose, initially recognized in Colorado mule deer. The discovery of CWD beyond the borders of Colorado and Wyoming, in Canada and as far east as New York, has led to its emergence as a prion disease of international importance. Epidemiological studies indicate that CWD is horizontally transmitted among free-ranging animals, potentially indirectly by prion-containing secreta or excreta contaminating the environment. Experimental CWD transmission attempts to other wild and domestic mammals and to transgenic mice expressing the prion protein of cattle, sheep, and humans have shed light on CWD species barriers. Transgenic mice expressing the cervid prion protein have proven useful for assessing the genetic influences of Prnp polymorphisms on CWD susceptibility. Accumulating evidence of CWD pathogenesis indicates that the misfolded prion protein or prion infectivity seems to be widely disseminated in many nonneural organs and in blood. This review highlights contemporary research findings in this prion disease of free-ranging wildlife.
\end{abstract}

\section{CWD / prion / TSE / cervid / amyloid}

Table of contents

1. Introduction 1

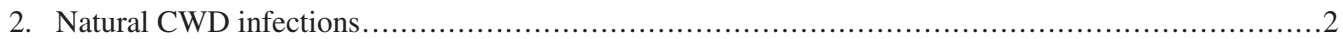

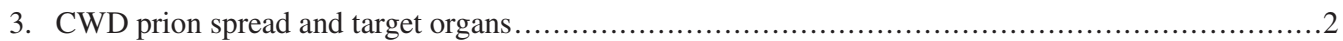

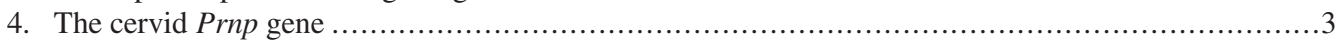

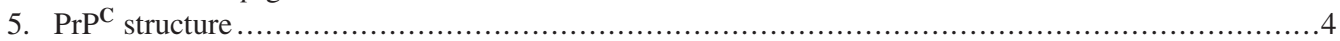

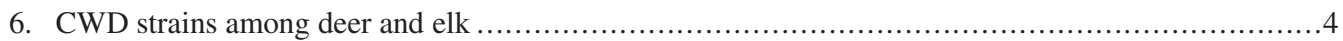

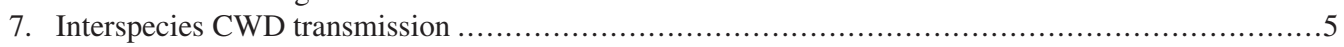

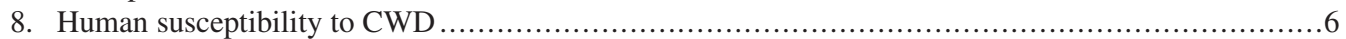

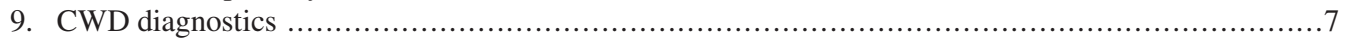

10. Tools for CWD research: cell lines and cervid PrP expressing transgenic mice ........................ 7

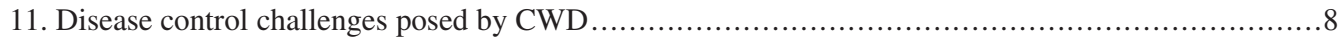

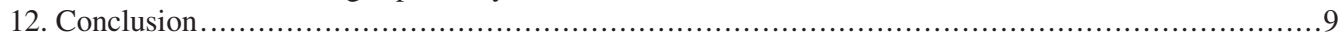

\section{INTRODUCTION}

Prion diseases, or transmissible spongiform encephalopathies (TSE), affect not only domestic and zoo animals, but also free-ranging wildlife. Chronic wasting disease (CWD) is a prion disease of mule deer (Odocoileus hemionus), white-tailed deer (Odocoileus virginianus), Rocky Mountain elk (Cervus ela-

* Corresponding author: csigurdson@ucsd.edu phus nelsoni), and Shira's moose (Alces alces shirasi) [4, 89, 90], and is only known to occur in North America and in South Korea [16, 39, 40, 93]. That said, international testing for CWD has been minimal with the exception of a CWD surveillance program in Germany [73].

TSE are believed to be caused by the accumulation of a misfolded, $\beta$-sheet rich conformer, $\mathrm{PrP}^{\mathrm{Sc}}$, of the cellular prion protein, 
$\operatorname{PrP}^{\mathrm{C}}$, which leads to neurodegeneration and ultimately death. In 1978, CWD was first recognized as a new TSE of captive mule deer in Colorado by pathologists Williams and Young [89]. Soon thereafter, a prion disease was reported in elk in Wyoming [90]. CWD was believed to be limited to this central region of the US for two decades. However, within the past 10 years, increased CWD testing has revealed more of the widespread distribution of CWD. Isolated, noncontinguous clusters of prion-infected cervids have been located as far west as Utah and extending east to New York and West Virginia ${ }^{1}$. Local prevalences have reached as high as 30\% of free-ranging deer [93]. In Canada, CWD cases have been diagnosed in farmed elk and white-tailed deer, as well as free-ranging deer in Saskatchewan and Alberta [39, 87]. The widespread occurrence of CWD in farmed and free-ranging cervids has led to a surge in CWD research, focused on understanding species susceptibility, transmission and pathogenesis, spatial epidemiology, diagnostic tools, strains, and cervid PrP structure. Transgenic mice expressing cervid $\operatorname{PrP}$ have been generated in five laboratories [10,41, 44, 52, 84], providing useful tools for CWD research. In this review, the latest advances in CWD research are discussed.

\section{NATURAL CWD INFECTIONS}

CWD is believed to be horizontally transmitted among cervids with high efficiency [54]. Therefore, the capacity for CWD to cross species barriers has been of great interest. Until recently, natural CWD infections were believed to infect only white-tailed deer, mule deer, and Rocky Mountain elk [89, $90,92]$. This ended in 2006, when a report indicated that Shira's moose could be orally-infected with brain homogenate from CWD-infected mule deer, and shortly thereafter a natural case of a CWD-infected moose was discovered $[4,42]$. Although moose populations overlap a geographically broad area of endemic CWD, moose are essentially

\footnotetext{
${ }^{1}$ http://www.aphis.usda.gov/vs/nahps/cwd/cwddistribution.html
}

solitary animals with home ranges of 2.2$18.9 \mathrm{~km}^{2}$ [48] which may help to limit CWD horizontal transmission. Another North American cervid species, the Porcupine caribou (Rangifer tarandus grantii), inhabits Alaska and the Yukon and Northwest Territories of Canada and congregates in dense herds of more than 10000 animals that can seasonally migrate over $1000 \mathrm{~km}$. Therefore caribou may be particularly susceptible to rapid disease dissemination since CWD seems to be efficiently transmitted among infected cervids [54]. CWD surveillance of Canadian caribou should be considered for early detection and management, and studies of caribou susceptibility to CWD are warranted.

\section{CWD PRION SPREAD AND TARGET ORGANS}

Collectively, CWD pathogenesis studies have revealed extensive deposition of $\mathrm{PrP}^{\mathrm{Sc}}$ in the central nervous system (CNS) and extraneural tissues (Fig. 1). The only other natural prion diseases that even approach this degree of systemic involvement are variant Creutzfeldt-Jakob disease (vCJD) in humans, sheep scrapie, and transmissible mink encephalopathy $[22,23,30,61,62]$. In mule deer, $\mathrm{PrP}^{\mathrm{Sc}}$ is detectable in the retropharyngeal lymph node within only six weeks following an oral exposure [76]. In a further study of the kinetics of prion infection in mule deer, Fox et al. showed that $\mathrm{PrP}^{\mathrm{Sc}}$ is widely distributed in lymphoid tissues by three months post-oral exposure when it is first detected in brain [17]. By nine months, $\operatorname{PrP}^{\mathrm{Sc}}$ was detected in the myenteric and submucosal plexi throughout the gastrointestinal tract and in the vagus nerve, and by 16 months, $\mathrm{PrP}^{\mathrm{Sc}} \mathrm{de}-$ posits were detectable throughout the brain and spinal cord. The Prnp genotype seemed to impact the infection kinetics in that mule deer that were SF heterozygous at codon 225 showed a delay in $\mathrm{PrP}^{\mathrm{Sc}}$ spread; $\mathrm{PrP}^{\mathrm{Sc}}$ was not detectable in the brain until 16 months postinoculation which was 13 months later than the 225SS deer. Perhaps the $225 \mathrm{~F}$ allele confers a dominant negative effect on the kinetics of this CWD strain, as has been described in sheep, where the $171 \mathrm{R}$ allele has been shown to have 


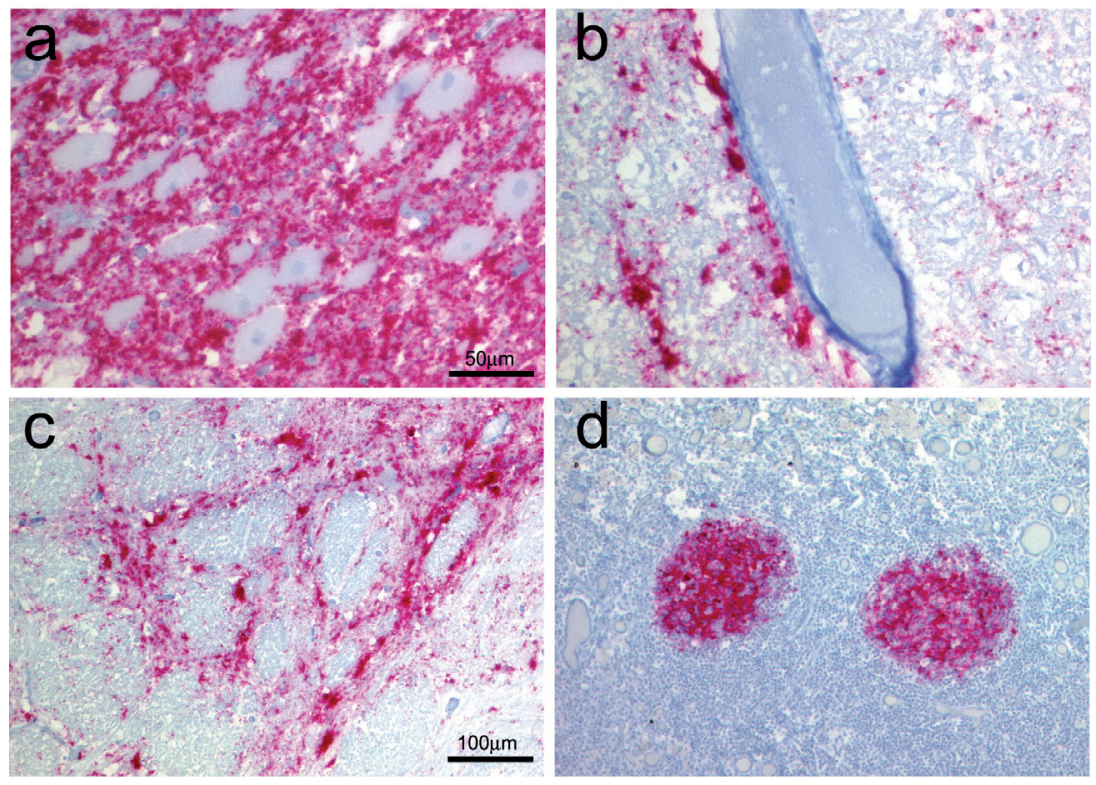

Figure 1. Brain and tonsil sections from a CWD-infected mule deer, immunolabelled for PrP. (a) Brain section at the level of the obex shows the dorsal motor nucleus of the vagus extensively labelled for $\operatorname{PrP}$ in the neuropil, however neuronal cell bodies are unstained. (b) Perivascular labelling in the obex is commonly seen in CWD-infected deer. (c) White matter tracts are labelled for PrP. (d) Tonsil contains PrP immunoreactivity within the lymphoid follicles. Uninfected deer show no PrP immunolabelling in brain or tonsils (data not shown). (A colour version of this figure is available at www.edpsciences.org/vetres.)

a dominant negative effect on prion susceptibility [20,33].

CWD pathogenesis seems to vary between deer and elk: $\operatorname{PrP}^{\mathrm{Sc}}$ levels have been found to be lower in lymphoid tissues of elk compared to deer [66]. Moreover, in a report of 226 CWD-infected elk, 28 had no $\operatorname{PrP}^{\mathrm{Sc}}$ in lymphoid tissues despite having $\mathrm{PrP}^{\mathrm{Sc}}$ in brain [81].

In addition to lymphoid tissues, $\mathrm{PrP}^{\mathrm{Sc}}$ or infectivity has been detected in other non-CNS tissues, including pancreas $[17,77]$, adrenal gland [17,77], and skeletal muscle [2]. Recently $\mathrm{PrP}^{\mathrm{Sc}}$ was described in cardiac muscle from 7 of $16(44 \%)$ white-tailed deer and from 12 of $17(71 \%)$ elk [35]. This is the first report of $\mathrm{PrP}^{\mathrm{Sc}}$ in cardiac muscle in any natural TSE.

The cellular and molecular mechanisms of systemic prion spread are under investigation in many laboratories. A recent report showed that blood from CWD-infected deer contained infectivity and could transmit prion disease via a blood transfusion [50]. This finding re- capitulates findings of blood infectivity transferred via transfusion from vCJD affected humans [61] and experimental from scrapie sick sheep [32], and indicates that prion transport throughout the body may include the blood as a potential vehicle.

\section{THE CERVID Prnp GENE}

Prnp is highly conserved, and few amino acid residues differ among cervids [1,34, 58]. However species specific polymorphisms exist, and accumulating evidence suggests that species-specific polymorphisms affect susceptibility to CWD infection with the presently existing strains. In naturally infected mule deer, serine homozygosity at Prnp codon 225 seems to increase risk for CWD infection, as the probability that a CWD-infected animal was $225 \mathrm{SS}$ was 30 times greater than for $\mathrm{S} / \mathrm{F}$ or FF when the frequency of genotypes was compared among CWD negative and positive deer ( $n=1482$ deer) [34]. As noted above, 
225SF mule deer had a delay in the kinetics of experimental infection [17].

Elk have a polymorphism at codon 132 (M/L) of Prnp, corresponding to polymorphic codon $129(\mathrm{M} / \mathrm{V})$ in humans [58]. Not only is this codon important for CJD susceptibility and strain typing [86], but it also seems to be influential for elk prion susceptibility. Among free-ranging and captive elk, animals expressing 132MM and 132ML were overrepresented among elk with CWD compared to uninfected controls [58]. In an experimental setting, three of four 132LL elk orally infected with CWD developed clinical disease by 59-64 months post-inoculation whereas $132 \mathrm{MM}$ or $132 \mathrm{ML}$ elk ( $n=2$ each) developed terminal clinical prion disease by 23 or 40 months post-inoculation, respectively, confirmed by immunohistochemistry and Western blot for $\operatorname{PrP}^{\mathrm{Sc}}[27,60]$. Therefore the $132 \mathrm{LL}$ and 132ML heterozygous elk had a 2-3 fold delay in the infection kinetics, indicating that the 132 polymorphism may influence prion conversion in elk.

White-tailed deer also have a polymorphism at Prnp codon 96 (S/G) [36]. Transgenic mice expressing cervid PrP of either allelic variant, denoted here as $\operatorname{tg}(\mathrm{CerPrP} 96 \mathrm{G})$ and $\operatorname{tg}(\mathrm{CerPrP96S})$, were exposed to deer CWD [52]. Whereas the $\operatorname{tg}($ CerPrP96G) mice were highly susceptible to infection and developed disease at 160 days post-infection, the $\operatorname{tg}(\mathrm{CerPrP96S})$ mice were completely resistant, with no clinical disease or $\mathrm{PrP}^{\mathrm{Sc}}$ deposits even at 600 dpi. It is possible, however, that the $\operatorname{tg}(\mathrm{CerPrP} 96 \mathrm{~S})$ mice may be converted by deer CWD derived from an animal that was SS homozygous at codon 96 . In naturally infected white-tailed deer, deer that expressed 96SS PrP had a lower risk for CWD infection, but were not resistant, since at least three of 7350 CWD infected deer were positive for $\mathrm{PrP}^{\mathrm{Sc}}$ in brain $[36,59]$. Other studies suggest that the $96 \mathrm{~S}$ allele delays CWD disease progression [95]. Perhaps these two allelic genotypes select for different CWD strains.

\section{PRP $^{\mathrm{C}}$ STRUCTURE}

The $\operatorname{PrP}^{\mathrm{C}}$ structure has been solved by nuclear magnetic resonance (NMR) analysis from recombinant prion protein from a library of vertebrate species [13, 21, 31, 45-47, 63]. The global architecture of the various mammalian PrP structures are nearly identical. Intriguingly, elk PrP possesses an extremely well-defined loop connecting the second alpha helix and beta sheet (amino acids 166-175), whereas the homologous region is flexibly disordered in human and bovine $\operatorname{PrP}^{\mathrm{C}}$ [21]. In the laboratory of Kurt Wüthrich, this loop region has been studied in detail, and the loop is thought to provide structural insights into species barriers for prion disease [12]. Further structural studies in two mutant mouse PrP variants derived from the elk PrP primary structure, $\mathrm{mPrP}[\mathrm{N} 174 \mathrm{~T}]$ and $\mathrm{mPrP}[\mathrm{S} 170 \mathrm{~N}$, $\mathrm{N} 174 \mathrm{~T}]$, have confirmed that the defined loop in the elk is due to two amino acid exchanges, as the $\mathrm{mPrP}[\mathrm{S} 170 \mathrm{~N}, \mathrm{~N} 174 \mathrm{~T}]$ has the conformationally identical rigid loop of the elk [21]. It is of great interest to determine whether the loop region of the elk influences TSE susceptibility and CWD transmission to other species.

\section{CWD STRAINS AMONG DEER AND ELK}

Prion strains, such as those seen in sheep scrapie, show distinct incubation periods in differentially susceptible inbred mice and lesions target discrete brain regions $[11,18,19]$. CWD in deer and elk has been considered a single disease entity, and Western blot glycoform patterns of $\mathrm{PrP}^{\mathrm{Sc}}$ are similar among deer and elk [67]. However, some new data indicate otherwise, suggesting that conformational variants, or strains, may exist. In a study by Raymond et al., Syrian golden hamsters were infected with mule deer or elk CWD, but with an incomplete attack rate; only 2 of 7 and 0 of 7 hamsters developed terminal disease, respectively. Indeed, second and third passage of the mule deer derived strain resulted in a short incubation period of only 85-89 days, whereas the elk-derived strain led to an incubation period of 408-544 days. Surprisingly, when mule deer CWD was first passaged in hamster PrP expressing transgenic mice and then into hamsters, a slowly replicating strain with a distinct clinical disease and $\mathrm{PrP}^{\mathrm{Sc}}$ deposition patterns in brain ensued. Therefore, two different strains could be passaged from 
a single mule deer CWD isolate, a rapid and a slowly replicating strain with differing disease phenotypes [70]. Alternatively, these strains could have been generated upon interspecies transmission [6].

We have also observed two strains arising from a single CWD-infected mule deer upon passage in transgenic mice overexpressing murine PrP. Here, mice developed different $\mathrm{PrP}^{\mathrm{Sc}}$ aggregate morphologies in brain, either dense, congophilic plaques or fine, diffuse aggregates which could be selectively passaged [78]. LaFauci et al. have reported that elk PrP expressing transgenic mice developed phenotypically divergent diseases when inoculated with either mule deer or elk CWD, which was suggestive of different strains among cervids [44]. In some of these studies, it is not clear whether mule deer and elk possess heterogeneous PrP aggregates (strain mixture), or whether the strains may have developed in the new host. However, Safar et al. have reported differing conformational characteristics for $\mathrm{PrP}^{\mathrm{Sc}}$ from CWD-infected white-tailed deer and elk directly, using a conformation dependent immunoassay (CDI) [71], which supports the existence of CWD strains. The possible existence of CWD strains is perhaps not entirely surprising, considering that there are genetic Prnp differences among deer and elk that could influence $\mathrm{PrP}^{\mathrm{Sc}}$ conformation $[34,36,58]$.

\section{INTERSPECIES CWD TRANSMISSION}

Wild predators and scavengers are presumably feeding on CWD-infected carcasses. Skeletal muscle has been shown to harbor CWD prion infectivity [2], underscoring that other species will almost certainly be exposed to CWD through feeding. However, CWD has not been successfully transmitted by oral inoculation to species outside of the cervid family, suggestive of a strong species barrier for heterologous PrP conversion. Ferrets (family Mustelidae) can be infected with deer CWD after intracerebral (ic) but not oral exposure [5, 80]. Raccoons resisted even ic infection for up to two years thus far [24]. Mountain lion (Puma concolor) susceptibility to experimental feeding of CWD prions is currently under investigation (M. Miller and L. Wolfe, personal communication).

Could wild rodents colonizing CWD- or scrapie-infected pastures serve as an environmental reservoir of prion infectivity? Interestingly, bank voles (Clethrionomys glareolus), are readily infected with CWD and sheep scrapie by intracerebral inoculation ([64]; U. Agrimi, unpublished data) and are considered as a potential reservoir for sheep scrapie [64]. Many vole species occur in North America $[65,83]$ and further research may determine whether voles enhance CWD or scrapie spread through environmental contamination.

Given that environmental contamination with CWD prions likely occurs [55], domestic ruminants may be exposed to CWD through common grazing areas. However, sheep and cattle appear to be poorly susceptible to mule deer CWD: ic inoculation with mule deer CWD succeeded to infect only 2 of 8 sheep [28]. Likewise, cattle have note proven to be infected after six years of co-grazing with CWD-infected mule deer, or six years following a direct oral exposure (six years post-inoculation) (M. Miller, personal communication). Even direct ic inoculation led to CWD infection in only 5 of 13 cattle (38\%) after 2-5 years [26]. In contrast, cattle are highly susceptible to white-tailed deer CWD with 12 of 14 animals developing neurologic disease and $\mathrm{PrP}^{\mathrm{Sc}}$ by only 22 months post-ic inoculation ( \pm 0.5 months) [29]. Further studies are planned to determine whether cattle are susceptible to white-tailed deer prions after an oral exposure (J. Richt, personal communication). The differential susceptibility of cattle to CWD from mule deer versus white-tailed deer suggests that CWD strains exist, and that CWD may differentially cross species barriers depending on the strain. Nevertheless, to date, natural CWD infections have been detected only in cervids.

Is the converse true, are cervids susceptible to prions from other species? Only one study has been performed on cervid susceptibility to sheep scrapie by the ic route, and showed that 3 of 6 elk developed neurologic signs, spongiform encephalopathy and $\mathrm{PrP}^{\mathrm{Sc}}$ in brain [25]. Further experiments to address this question 
may be interesting since sheep scrapie is considered a possible source for CWD in North America [89,91].

\section{HUMAN SUSCEPTIBILITY TO CWD}

Millions of North Americans hunt deer and elk (US Department of the Interior, Census Bureau), and there is no doubt that people have been exposed to CWD through venison consumption, particularly in light of recent data showing CWD prions in muscle [2]. Human susceptibility to CWD or to other newly emerging animal TSE $[9,14]$ is still unclear, although we can be somewhat reassured in that there have been no large scale outbreaks of human TSE cases in Colorado and Wyoming, where CWD has existed for decades [51]. Up until approximately 10 years ago, autopsies were not performed on suspect human TSE cases in many states due to biosafety concerns, therefore the diagnosis of potential new TSE strains has been hampered. This indicates that clinical TSE diagnoses in humans were not confirmed, nor was any strain typing done to look for the appearance of potentially subtle or unusual pathological or biochemical phenotypes of a new TSE strain. Fortunately, the autopsy rate for suspect cases is improving. At the National Prion Disease Pathology Surveillance Center at Case Western Reserve University (Cleveland, Ohio), Creutzfeldt-Jakob disease (CJD) suspect cases are studied and classified by CJD subtype. Thus far, twentyseven CJD patients who regularly consumed venison were reported to the Surveillance Center, however there have been no unusual or novel prion subtypes that might indicate the appearance of a new prion strain $[7,41]$.

Other indirect studies of human susceptibility to CWD also suggest that the risk is low. In biochemical conversion studies, Raymond et al. [68] showed that the efficiency of CWD to convert recombinant human PrP into amyloid fibrils was low, but similar to that of both BSE and scrapie fibrils to do the same. These results suggest that there is a molecular incompatibility in the conversion of human $\operatorname{PrP}^{\mathrm{C}}$ by CWD, sheep scrapie, or BSE, and that cross species infections in humans may be rare events.
To determine whether common $\mathrm{PrP}^{\mathrm{Sc}}$ strain features may link CWD and CJD, histopathology and the $\mathrm{PrP}^{\mathrm{Sc}}$ biochemical characteristics from deer and elk were compared with that of humans with sporadic CJD (sCJD) cases that are methionine homozygous at codon 129 of the Prnp gene by Xie et al. [96]. However, strain features including histologic profile, target organs, and glycoform patterns will not necessarily remain the same upon crossing species barriers $[5,6,8,57]$. The $\operatorname{PrP}^{\mathrm{Sc}}$ form is cleaved by proteinase-K $(\mathrm{PK})$ at different sites depending on the conformation of the protein and may aid determination of whether the $\mathrm{PrP}^{\mathrm{Sc}}$ conformation is similar. By Western blot (SDS-PAGE) of elk CWD, the unglycosylated PK-resistant $\mathrm{PrP}^{\mathrm{Sc}}$ migrated to $21 \mathrm{kDa}$, similar to sCJD (MM1 subtype) and the PK cleavage site was the same, occurring at residues 78 and 82 as assessed by $\mathrm{N}$-terminal sequencing. Conformational stability was evaluated by measuring the $\mathrm{PrP}^{\mathrm{Sc}}$ stability under partially denaturing conditions and also showed no significant difference between elk CWD and SCJD MM1 $\mathrm{PrP}^{\mathrm{Sc}}$. However, elk CWD and human SCJD MM1 strains exhibited distinct glycoform patterns by two dimensional gel electrophoresis, suggesting that the strains differed. Future studies may incorporate use of luminescent conjugated polymers, which were recently shown to distinguish naturally- and experimentally-derived prion strains [79].

To study elk-human prion species barriers, Kong et al. inoculated elk CWD into transgenic mice expressing either human PrP or elk PrP. Whereas the elk PrP expressing mice developed disease after only 118 142 days post-inoculation, human PrP expressing mice $(129 \mathrm{M})$ did not develop any features of TSE after more than 657 or more than 756 days [41]. In accordance with these results, Tamgüney et al. also reported that human PrP overexpressing mice were not susceptible to nine CWD isolates from mule deer, white-tailed deer, and elk [84]. However, mice have a limited lifespan and further passages may be necessary to detect low levels of prion pinfectivity that may be present subclinically.

Although indirect evidence is accumulating that there may be a robust species barrier 
for CWD transmission to humans, one report indicates nonhuman primate susceptibility to CWD. Intracerebral inoculation of squirrel monkeys (Saimiri sciureus) demonstrated a positive CWD transmission [49]. Among nonhuman primates, however, the Prnp sequence of the new world monkeys are the most distant from humans [72], and therefore may not indicate that human prion protein conversion would be induced by CWD $\mathrm{PrPS}^{\mathrm{Sc}}$.

\section{CWD DIAGNOSTICS}

Clinical signs of CWD in deer and elk are unspecific and subtle in early disease and commonly include weight loss and behavioral changes such as isolation from the herd and depression. Other signs may include hypersalivation, polydipsia/polyuria, ataxia, and occasionally increased regurgitation and/or esophageal distension. Therefore sensitive, specific, and rapid ante-mortem CWD assays are critical for accurate diagnosis. Removal of infected animals from a herd, particularly in US National Parks where culling of only known infected individuals is often the preferred method of management (M. Wild, personal communication). To survey and manage CWD in Rocky Mountain National Park and adjacent Estes Park in Colorado, mule deer were anesthetized, radiocollared, and tonsil biopsies collected and tested (M. Wild, personal communication; [94]). Any prioninfected animals were then located by radiotelemetry and euthanized. Therefore, intensive CWD management can be costly and labor intensive.

Rectal biopsies have been evaluated as an alternative to tonsil biopsies for large scale surveillance of free-ranging or captive deer. $\mathrm{PrP}^{\mathrm{Sc}}$ was readily detected by IHC in rectal lymphoid follicles from experimentally infected deer, where 19 of 19 deer were positive by one year after oral inoculation. In naturallyinfected mule deer, 45 of 50 subclinical and terminal CWD-infected deer, as determined by immunohistochemistry on tonsil or retropharyngeal lymph nodes, were also positive by rectal biopsy [95]. Rectal biopsies to diagnose CWD in elk may also be suitable, as one study showed a strong correlation between tonsil, rectal mucosa, and brain in CWD positive elk, although one of seven elk with early CWD was tonsil positive, but rectal mucosa negative [82].

$\mathrm{PrP}^{\mathrm{Sc}}$ detection in CWD-infected deer blood has been a challenge to develop as an antemortem diagnostic tool. $\mathrm{PrP}^{\mathrm{Sc}}$ was recently reported as detectable in deer blood using an antibody ELISA with signal amplification of antibody conjugated DNA catalyzed by $\mathrm{T} 7$ RNA polymerase [15].

Protein misfolding cyclic amplification (PMCA) can be used to amplify $\mathrm{PrP}^{\mathrm{Sc}}$ from CWD-infected deer, and should be valuable for $\mathrm{PrP}^{\mathrm{Sc}}$ detection from tissues and body fluids containing low levels of infectivity, for improved understanding of CWD pathogenesis, and also to detect animals in early stages of infection [43]. Atarashi et al. [3] developed a highly sensitive PMCA amplification technique whereby recombinant, natively folded $\mathrm{PrP}$ monomers is used to amplify $\mathrm{PrP}^{\mathrm{Sc}}$; as little as $50 \mathrm{ag}$ of $\mathrm{PrP}^{\mathrm{Sc}}$ was detectable. Therefore methods for sensitive detection of $\mathrm{PrP}^{\mathrm{Sc}}$ are substantially improving.

\section{TOOLS FOR CWD RESEARCH: CELL LINES AND CERVID PrP EXPRESSING TRANSGENIC MICE}

Until recently, few techniques were available to detect CWD prion infectivity, or to test compounds to disrupt prion conversion. A CWD-susceptible cell line derived from cervid brain fibroblasts has been used to screen inhibitors of CWD infection, for example, pentosan polysulfate [69]. This CWD specific assay may identify compounds that inhibit CWD propagation.

Browning et al. developed the first transgenic mouse expressing cervid PrP [10], which was subsequently utilized as a bioassay to detect CWD prions in muscle [2]. Several transgenic mice expressing cervid PrP have since been produced using different constructs and sequences [10,41, 44, 52,84] (detailed in Tab. I). The cervid PrP-expressing transgenic mice provide an important tool for investigations of CWD and other TSE, particularly for cross-species transmission studies. In a study by Trifilo et al. cervid PrP expressing mice 
Table I. Transgenic mice developed for CWD research.

\begin{tabular}{|c|c|c|c|c|c|c|}
\hline $\begin{array}{l}\text { Prnp } \\
\text { gene }^{1}\end{array}$ & Lines $^{2}$ & Promoter & Expression $^{3}$ & $\begin{array}{l}\text { Cervid CWD: } \\
\text { primary } \\
\text { passage }^{4}\end{array}$ & $\begin{array}{l}\text { Average } \\
\text { incubation } \\
\text { period (days) }\end{array}$ & Reference \\
\hline Mule deer & $\operatorname{Tg}($ CerPrP $) 1536^{+/-}$ & Hamster prion & $5 \mathrm{X} \mathrm{WT}$ & MD, elk & $230-260$ & [10] \\
\hline Mule deer & $\operatorname{Tg}($ CerPrP $) 1534^{+/-}$ & Hamster prion & $3 \mathrm{X}$ WT & MD & 270 & [10] \\
\hline Deer $(96 G)$ & Line $33^{+/-}$ & Mouse prion & $>$deer & $\begin{array}{l}\text { WTD, MD, } \\
\text { elk }\end{array}$ & $200-400$ & [52] \\
\hline Deer $(96 G)$ & Line $15^{+/-}$ & Mouse prion & $1 \mathrm{X}$ deer & $\begin{array}{l}\text { WTD, MD, } \\
\text { elk }\end{array}$ & $160-450$ & [52] \\
\hline Deer $(96 G)$ & Line $39^{+/-}$ & Mouse prion & $1 \mathrm{X}$ deer & $\begin{array}{l}\text { WTD, MD, } \\
\text { elk }\end{array}$ & $200-400$ & [52] \\
\hline Deer $(96 S)$ & Line $60^{+/-}$ & Mouse prion & $>$deer & $\begin{array}{l}\text { WTD, MD, } \\
\text { elk }\end{array}$ & $\begin{array}{l}\text { resistant } \\
(>600 \text { days) }\end{array}$ & [52] \\
\hline Deer $(96 S)$ & Line $80^{+/-}$ & Mouse prion & $1 \mathrm{X}$ deer & $\begin{array}{l}\text { WTD, MD, } \\
\text { elk }\end{array}$ & $\begin{array}{l}\text { resistant } \\
(>600 \text { days })\end{array}$ & [52] \\
\hline Elk & $\mathrm{TgElk}^{+/+}$ & Hamster prion & $2.5 \mathrm{WT}$ & $\mathrm{MD}$, elk & $\begin{array}{l}95 \text { (MD); } \\
130 \text { (elk) }\end{array}$ & [44] \\
\hline Elk & $\operatorname{Tg}(\operatorname{ElkPrP}) 12577^{+/-}$ & Hamster prion & 2X WT & $\begin{array}{l}\text { WTD, MD, } \\
\text { elk }\end{array}$ & $\begin{array}{l}180 \text { (WTD); } \\
200 \text { (MD); } \\
185 \text { (elk) }\end{array}$ & [84] \\
\hline Elk & $\operatorname{Tg}($ ElkPrP $) 12580^{+/-}$ & Hamster prion & 2X WT & Elk & 205 & [84] \\
\hline Elk & $\operatorname{Tg}($ ElkPrP $) 3934^{+/+}$ & Hamster prion & 3X WT & Elk & 145 & [84] \\
\hline Elk & $\operatorname{Tg}($ ElkPrP $) 12584^{+/-}$ & Hamster prion & 3X WT & Elk & 150 & [84] \\
\hline Deer & $\operatorname{Tg}(\mathrm{DePrP}) 10945^{+/-}$ & Hamster prion & $1 \mathrm{XWT}$ & $\begin{array}{l}\text { WTD, MD, } \\
\text { elk }\end{array}$ & $\begin{array}{l}400 \text { (WTD); } \\
340 \text { (MD) } \\
290 \text { (MD); } \\
330 \text { (elk) }\end{array}$ & [84] \\
\hline Deer & $\operatorname{Tg}(\mathrm{DePrP}) 10969^{+/-}$ & Hamster prion & 1X WT & $\mathrm{MD}$, elk & $\begin{array}{l}325 \text { (MD); } \\
305 \text { (elk) }\end{array}$ & [84] \\
\hline Elk & $\operatorname{Tg} 12^{+/-}$ & Mouse prion & 2X WT & Elk & $120-140$ & [41] \\
\hline
\end{tabular}

${ }^{1}$ All cervid constructs are $96 \mathrm{G}$ except for the two $96 \mathrm{~S}$ transgenic mice produced by Meade-White et al. [52]. All deer constructs are $138 \mathrm{~S}$. All elk constructs are $132 \mathrm{M}$.

${ }^{2}$ All mice are on a $\operatorname{Prnp}^{0 / 0}$ background. Transgene homozygosity is indicated by ${ }^{+/+}$, and hemizygosity as ${ }^{+/-}$.

${ }^{3}$ WT indicates wild-type murine PrP levels.

${ }^{4} \mathrm{WTD}=$ White-tailed deer; MD $=$ mule deer.

${ }^{5}$ Incubation period defined as time from inoculation to terminal disease.

were orally susceptible to CWD, enabling kinetic studies of CWD pathogenesis [85]. All together, these experiments demonstrate the utility of these mice as a tool for studying CWD transmission, species barriers, and understanding the pathogenesis of CWD through tissue and body fluid bioassay.

\section{DISEASE CONTROL CHALLENGES POSED BY CWD}

Evidence is building that indicates efficient horizontal transmission occurs in CWD, indeed a complicating aspect in disease control [91]. Potential transmission mechanisms 
range from spread via direct contact among animals to environmental exposure through grazing in areas contaminated by prioninfected secretions, excretions (saliva, urine, feces), tissues (placenta), or decomposed carcasses. Recently, in a breakthrough finding, saliva from CWD-infected deer was shown to transmit prion disease [50]. An additional experiment by Miller et al. showed that CWDinfected carcasses allowed to decay naturally in confined pastures can lead to CWD infections in captive deer, demonstrating the potential for environmental contamination to spread infection [55]. Modelling studies have provided further support that environmental contamination is likely playing a significant role in transmitting CWD $[53,56]$. Additionally, infectious prions have been demonstrated to bind soil particles and remain infectious to animals by both intracerebral and oral exposure routes $[37,38]$. Prion infectivity has been recovered from soil more than two years after experimental exposure to prions, suggesting the soil may serve as a reservoir for CWD prions [75]. Taken together, these results indicate that there may even be multiple sources for CWD exposure, perhaps through direct contact and environmental routes.

Significant challenges to CWD eradication exist in free-ranging cervids. Infected deer and elk range over a broad geographic region, and even previously surmised geographic barriers such as the Continental Divide have proven passable by infected animals. Ridding the environment of CWD-contaminated soil or even CWD-infected carcasses is not possible. Moreover, the available ante-mortem diagnostic tests for surveillance are laborious and impractical for large numbers of free-ranging animals [74, 88, 95]. Therefore for a wildlife manager, this disease is costly to survey and difficult to control.

\section{CONCLUSION}

CWD in cervids is efficiently transmitted, likely more than any other TSE in animals or humans. Therefore, it is unlikely that this TSE can be eradicated. Perhaps through an improved understanding of transmission routes, biological factors influencing pathogenesis, and the molecular basis of CWD prion conversion, a targeted strategy for interrupting disease spread may be developed.

Acknowledgements. I thank Drs. Michael Miller, Jason Bartz and Mathias Heikenwalder for critical review of the manuscript.

\section{REFERENCES}

[1] Aguzzi A., Polymenidou M., Mammalian prion biology. One century of evolving concepts, Cell (2004) 116:313-327.

[2] Angers R.C., Browning S.R., Seward T.S., Sigurdson C.J., Miller M.W., Hoover E.A., Telling G.C., Prions in skeletal muscles of deer with chronic wasting disease, Science (2006) 311:1117.

[3] Atarashi R., Moore R.A., Sim V.L., Hughson A.G., Dorward D.W., Onwubiko H.A., et al., Ultrasensitive detection of scrapie prion protein using seeded conversion of recombinant prion protein, Nat. Methods (2007) 4:645-650.

[4] Baeten L.A., Powers B.E., Jewell J.E., Spraker T.R., Miller M.W., A natural case of chronic wasting disease in a free-ranging moose (Alces alces shirasi), J. Wildl. Dis. (2007) 43:309-314.

[5] Bartz J.C., Marsh R.F., McKenzie D.I., Aiken J.M., The host range of chronic wasting disease is altered on passage in ferrets, Virology (1998) 251:297-301.

[6] Bartz J.C., Bessen R.A., McKenzie D., Marsh R.F., Aiken J.M., Adaptation and selection of prion protein strain conformations following interspecies transmission of transmissible mink encephalopathy, J. Virol. (2000) 74:5542-5547.

[7] Belay E.D., Maddox R.A., Williams E.S., Miller M.W., Gambetti P., Schonberger L.B., Chronic wasting disease and potential transmission to humans, Emerging Infect. Dis. (2004) 10:977-984.

[8] Bellworthy S.J., Hawkins S.A., Green R.B., Blamire I., Dexter G., Dexter I., et al., Tissue distribution of bovine spongiform encephalopathy infectivity in Romney sheep up to the onset of clinical disease after oral challenge, Vet. Rec. (2005) 156:197-202.

[9] Benestad S.L., Sarradin P., Thu B., Schönheit J., Tranulis M.A., Bratberg B., Cases of scrapie with unusual features in Norway and designation of a new type, Nor98, Vet. Rec. (2003) 153:202-208.

[10] Browning S.R., Mason G.L., Seward T., Green M., Eliason G.A., Mathiason C., et al., Transmission of prions from mule deer and elk with chronic wasting disease to transgenic mice expressing cervid PrP, J. Virol. (2004) 78:13345-13350.

[11] Bruce M.E., McBride P.A., Farquhar C.F., Precise targeting of the pathology of the sialoglycoprotein, PrP, and vacuolar degeneration in mouse scrapie, Neurosci. Lett. (1989) 102:1-6.

[12] Calzolai L., Lysek D.A., Guntert P., von Schroetter C., Riek R., Zahn R., Wüthrich K., NMR structures of three single-residue variants of the human prion protein, Proc. Natl. Acad. Sci. USA (2000) 97:8340-8345. 
[13] Calzolai L., Lysek D.A., Pérez D.R., Güntert P., Wüthrich K., Prion protein NMR structures of chickens, turtles, and frogs, Proc. Natl. Acad. Sci. USA (2005) 102:651-655.

[14] Casalone C., Zanusso G., Acutis P., Ferrari S., Capucci L., Tagliavini F., Monaco S., Caramelli M., Identification of a second bovine amyloidotic spongiform encephalopathy: molecular similarities with sporadic Creutzfeldt-Jakob disease, Proc. Natl. Acad. Sci. USA (2004) 101:3065-3070.

[15] Chang B., Cheng X., Yin S., Pan T., Zhang H., Wong P., et al., Test for detection of diseaseassociated prion aggregate in the blood of infected but asymptomatic animals, Clin. Vaccine Immunol. (2007) 14:36-43.

[16] Dubé C., Mehren K.G., Barker I.K., Peart B.L., Balachandran A., Retrospective investigation of chronic wasting disease of cervids at the Toronto Zoo, 1973-2003, Can. Vet. J. (2006) 47:1185-1193.

[17] Fox K.A., Jewell J.E., Williams E.S., Miller M.W., Patterns of $\mathrm{PrP}^{\mathrm{CWD}}$ accumulation during the course of chronic wasting disease infection in orally inoculated mule deer (Odocoileus hemionus), J. Gen. Virol. (2006) 87:3451-3461.

[18] Fraser H., Dickinson A.G., The sequential development of the brain lesion of scrapie in three strains of mice, J. Comp. Pathol. (1968) 78:301-311.

[19] Fraser H., Dickinson A.G., Scrapie in mice. Agent-strain differences in the distribution and intensity of grey matter vacuolation, J. Comp. Pathol. (1973) 83:29-40.

[20] González L., Martin S., Begara-McGorum I., Hunter N., Houston F., Simmons M., Jeffrey M., Effects of agent strain and host genotype on PrP accumulation in the brain of sheep naturally and experimentally affected with scrapie, J. Comp. Pathol. (2002) 126:17-29.

[21] Gossert A.D., Bonjour S., Lysek D.A., Fiorito F., Wüthrich K., Prion protein NMR structures of elk and of mouse/elk hybrids, Proc. Natl. Acad. Sci. USA (2005) 102:646-650.

[22] Hadlow W.J., Kennedy R.C., Race R.E., Natural infection of Suffolk sheep with scrapie virus, J. Infect. Dis. (1982) 146:657-664.

[23] Hadlow W.J., Race R.E., Kennedy R.C., Temporal distribution of transmissible mink encephalopathy virus in mink inoculated subcutaneously, J. Virol. (1987) 61:3235-3240.

[24] Hamir A.N., Miller J.M., Cutlip R.C., Stack M.J., Chaplin M.J., Jenny A.L., Williams E.S., Experimental inoculation of scrapie and chronic wasting disease agents in raccoons (Procyon lotor), Vet. Rec. (2003) 153:121-123.

[25] Hamir A.N., Miller J.M., Cutlip R.C., Kunkle R.A., Jenny A.L., Stack M.J., et al., Transmission of sheep scrapie to elk (Cervus elaphus nelsoni) by intracerebral inoculation: final outcome of the experiment, J. Vet. Diagn. Invest. (2004) 16:316-321.

[26] Hamir A.N., Kunkle R.A., Cutlip R.C., Miller J.M., O’Rourke K.I., Williams E.S., et al.,
Experimental transmission of chronic wasting disease agent from mule deer to cattle by the intracerebral route, J. Vet. Diagn. Invest. (2005) 17:276-281.

[27] Hamir A.N., Gidlewski T., Spraker T.R., Miller J.M., Creekmore L., Crocheck M., et al., Preliminary observations of genetic susceptibility of elk (Cervus elaphus nelsoni) to chronic wasting disease by experimental oral inoculation, J. Vet. Diagn. Invest. (2006) 18:110-114.

[28] Hamir A.N., Kunkle R.A., Cutlip R.C., Miller J.M., Williams E.S., Richt J.A., Transmission of chronic wasting disease of mule deer to Suffolk sheep following intracerebral inoculation, J. Vet. Diagn. Invest. (2006) 18:558-565.

[29] Hamir A.N., Miller J.M., Kunkle R.A., Hall S.M., Richt J.A., Susceptibility of cattle to first-passage intracerebral inoculation with chronic wasting disease agent from white-tailed deer, Vet. Pathol. (2007) 44:487-493.

[30] Head M.W., Ritchie D., Smith N., McLoughlin V., Nailon W., Samad S., et al., Peripheral tissue involvement in sporadic, iatrogenic, and variant CreutzfeldtJakob disease: an immunohistochemical, quantitative, and biochemical study, Am. J. Pathol. (2004) 164:143153.

[31] Hornemann S., Schorn C., Wüthrich K., NMR structure of the bovine prion protein isolated from healthy calf brains, EMBO Rep. (2004) 5:1159-1164. [32] Houston F., Foster J.D., Chong A., Hunter N., Bostock C.J., Transmission of BSE by blood transfusion in sheep, Lancet (2000) 356:999-1000.

[33] Hunter N., Foster J.D., Goldmann W., Stear M.J., Hope J., Bostock C., Natural scrapie in a closed flock of Cheviot sheep occurs only in specific PrP genotypes, Arch. Virol. (1996) 141:809-824.

[34] Jewell J.E., Conner M.M., Wolfe L.L., Miller M.W., Williams E.S., Low frequency of PrP genotype $225 \mathrm{SF}$ among free-ranging mule deer (Odocoileus hemionus) with chronic wasting disease, J. Gen. Virol. (2005) 86:2127-2134.

[35] Jewell J.E., Brown J., Kreeger T., Williams E.S., Prion protein in cardiac muscle of elk (Cervus elaphus nelsoni) and white-tailed deer (Odocoileus virginianus) infected with chronic wasting disease, J. Gen. Virol. (2006) 87:3443-3450.

[36] Johnson C., Johnson J., Vanderloo J.P., Keane D., Aiken J.M., McKenzie D., Prion protein polymorphisms in white-tailed deer influence susceptibility to chronic wasting disease, J. Gen. Virol. (2006) 87:2109-2114.

[37] Johnson C.J., Phillips K.E., Schramm P.T., McKenzie D., Aiken J.M., Pedersen J.A., Prions adhere to soil minerals and remain infectious, PLoS Pathog. (2006) 2:e32.

[38] Johnson C.J., Pedersen J.A., Chappell R.J., McKenzie D., Aiken J.M., Oral transmissibility of prion disease is enhanced by binding to soil particles, PLoS Pathog. (2007) 3:e93.

[39] Kahn S., Dubé C., Bates L., Balachandran A., Chronic wasting disease in Canada: Part 1, Can. Vet. J. (2004) 45:397-404. 
[40] Kim T.Y., Shon H.J., Joo Y.S., Mun U.K., Kang K.S., Lee Y.S., Additional cases of chronic wasting disease in imported deer in Korea, J. Vet. Med. Sci. (2005) 67:753-759.

[41] Kong Q., Huang S., Zou W., Vanegas D., Wang M., Wu D., et al., Chronic wasting disease of elk: transmissibility to humans examined by transgenic mouse models, J. Neurosci. (2005) 25:7944-7949.

[42] Kreeger T.J., Montgomery D.L., Jewell J.E., Schultz W., Williams E.S., Oral transmission of chronic wasting disease in captive Shira's moose, J. Wildl. Dis. (2006) 42:640-645.

[43] Kurt T.D., Perrott M.R., Wilusz C.J., Wilusz J., Supattapone S., Telling G.C., et al., Efficient in vitro amplification of chronic wasting disease $\operatorname{PrP}^{\mathrm{RES}}$, J. Virol. (2007) 81:9605-9608.

[44] LaFauci G., Carp R.I., Meeker H.C., Ye X., Kim J.I., Natelli M., et al., Passage of chronic wasting disease prion into transgenic mice expressing Rocky Mountain elk (Cervus elaphus nelsoni) $\operatorname{PrP}^{\mathrm{C}}$, J. Gen. Virol. (2006) 87:3773-3780.

[45] López Garcia F., Zahn R., Riek R., Wüthrich K., NMR structure of the bovine prion protein, Proc. Natl. Acad. Sci. USA (2000) 97:8334-8339.

[46] Lysek D.A., Nivon L.G., Wüthrich K., Amino acid sequence of the Felis catus prion protein, Gene (2004) 341:249-253.

[47] Lysek D.A., Schorn C., Nivon L.G., Esteve-Moya V., Christen B., Calzolai L., et al., Prion protein NMR structures of cats, dogs, pigs, and sheep, Proc. Natl. Acad. Sci. USA (2005) 102:640-645.

[48] MacDonald D., Mammals of Europe, Princeton, Princeton University Press, 1993.

[49] Marsh R.F., Kincaid A.E., Bessen R.A., Bartz J.C., Interspecies transmission of chronic wasting disease prions to squirrel monkeys (Saimiri sciureus), J. Virol. (2005) 79:13794-13796.

[50] Mathiason C.K., Powers J.G., Dahmes S.J., Osborn D.A., Miller K.V., Warren R.J., et al., Infectious prions in the saliva and blood of deer with chronic wasting disease, Science (2006) 314:133-136. [51] Mawhinney S., Pape W.J., Forster J.E., Anderson C.A., Bosque P., Miller M.W., Human prion disease and relative risk associated with chronic wasting disease, Emerging Infect. Dis. (2006) 12:1527-1535.

[52] Meade-White K., Race B., Trifilo M., Bossers A., Favara C., Lacasse R., et al., Resistance to chronic wasting disease in transgenic mice expressing a naturally occurring allelic variant of deer prion protein, J. Virol. (2007) 81:4533-4539.

[53] Miller M.W., Williams E.S., McCarty C.W., Spraker T.R., Kreeger T.J., Larsen C.T., Thorne E.T., Epizootiology of chronic wasting disease in freeranging cervids in Colorado and Wyoming, J. Wildl. Dis. (2000) 36:676-690.

[54] Miller M.W., Williams E.S., Prion disease: horizontal prion transmission in mule deer, Nature (2003) 425:35-36.

[55] Miller M.W., Williams E.S., Hobbs N.T., Wolfe L.L., Environmental sources of prion transmission in mule deer, Emerging Infect. Dis. (2004) 10:10031006.

[56] Miller M.W., Hobbs N.T., Tavener S.J., Dynamics of prion disease transmission in mule deer, Ecol. Appl. (2006) 16:2208-2214.

[57] Nonno R., Bari M.A., Cardone F., Vaccari G., Fazzi P., Dell'Omo G., et al., Efficient transmission and characterization of Creutzfeldt-Jakob disease strains in bank voles, PLoS Pathog. (2006) 2:e12.

[58] O’Rourke K.I., Besser T.E., Miller M.W., Cline T.F., Spraker T.R., Jenny A.L., et al., PrP genotypes of captive and free-ranging Rocky Mountain elk (Cervus elaphus nelsoni) with chronic wasting disease, J. Gen. Virol. (1999) 80:2765-2769.

[59] O'Rourke K.I., Spraker T.R., Hamburg L.K., Besser T.E., Brayton K.A., Knowles D.P., Polymorphisms in the prion precursor functional gene but not the pseudogene are associated with susceptibility to chronic wasting disease in white-tailed deer, J. Gen. Virol. (2004) 85:1339-1346.

[60] O’Rourke K.I., Spraker T.R., Zhuang D., Greenlee J.J., Gidlewski T.E., Hamir A.N., Elk with a long incubation prion disease phenotype have a unique PrPd profile, Neuroreport (2007) 18:1935-1938.

[61] Peden A.H., Head M.W., Ritchie D.L., Bell J.E., Ironside J.W., Preclinical vCJD after blood transfusion in a PRNP codon 129 heterozygous patient, Lancet (2004) 364:527-529.

[62] Peden A.H., Ritchie D.L., Head M.W., Ironside J.W., Detection and localization of $\operatorname{PrP}^{\mathrm{Sc}}$ in the skeletal muscle of patients with variant, iatrogenic, and sporadic forms of Creutzfeldt-Jakob disease, Am. J. Pathol. (2006) 168:927-935.

[63] Pérez D.R., Wüthrich K., NMR assignment of the Xenopus laevis prion protein fragment xlPrP (98-226), J. Biomol. NMR (2005) 31:260.

[64] Piening N., Nonno R., Di Bari M., Walter S., Windl O., Agrimi U., et al., Conversion efficiency of bank vole prion protein in vitro is determined by residues 155 and 170, but does not correlate with the high susceptibility of bank voles to sheep scrapie in vivo, J. Biol. Chem. (2006) 281:9373-9384.

[65] Questad E.J., Foster B.L., Vole disturbances and plant diversity in a grassland metacommunity, Oecologia (2007) 153:341-351.

[66] Race B.L., Meade-White K.D., Ward A., Jewell J., Miller M.W., Williams E.S., et al., Levels of abnormal prion protein in deer and elk with chronic wasting disease, Emerging Infect. Dis. (2007) 13:824-830.

[67] Race R.E., Raines A., Baron T.G., Miller M.W., Jenny A., Williams E.S., Comparison of abnormal prion protein glycoform patterns from transmissible spongiform encephalopathy agent-infected deer, elk, sheep, and cattle, J. Virol. (2002) 76:12365-12368.

[68] Raymond G.J., Bossers A., Raymond L.D., O'Rourke K.I., McHolland L.E., Bryant P.K. III, et al., Evidence of a molecular barrier limiting susceptibility of humans, cattle and sheep to chronic wasting disease, EMBO. J. (2000) 19:4425-4430. 
[69] Raymond G.J., Olsen E.A., Lee K.S., Raymond L.D., Bryant P.K. III, Baron G.S., et al., Inhibition of protease-resistant prion protein formation in a transformed deer cell line infected with chronic wasting disease, J. Virol. (2006) 80:596-604.

[70] Raymond G.J., Raymond L.D., Meade-White K.D., Hughson A.G., Favara C., Gardner D., et al., Transmission and adaptation of chronic wasting disease to hamsters and transgenic mice: evidence for strains, J. Virol. (2007) 81:4305-4314.

[71] Safar J.G., Scott M., Monaghan J., Deering C., Didorenko S., Vergara J., et al., Measuring prions causing bovine spongiform encephalopathy or chronic wasting disease by immunoassays and transgenic mice, Nat. Biotechnol. (2002) 20:1147-1150.

[72] Schätzl H.M., Da Costa M., Taylor L., Cohen F.E., Prusiner S.B., Prion protein gene variation among primates, J. Mol. Biol. (1995) 245:362-374.

[73] Schettler E., Steinbach F., Eschenbacher-Kaps I., Gerst K., Muessdoerffer F., Risch K., et al., Surveillance for prion disease in cervids, Germany, Emerging Infect. Dis. (2006) 12:319-322.

[74] Schuler K.L., Jenks J.A., DePerno C.S., Wild M.A., Swanson C.C., Tonsillar biopsy test for chronic wasting disease: two sampling approaches in mule deer and white-tailed deer, J. Wildl. Dis. (2005) 41:820 824.

[75] Seidel B., Thomzig A., Buschmann A., Groschup M.H., Peters R., Beekes M., Terytze K., Scrapie Agent (Strain $263 \mathrm{~K}$ ) can transmit disease via the oral route after persistence in soil over years, PLoS ONE (2007) 2:e435.

[76] Sigurdson C.J., Williams E.S., Miller M.W., Spraker T.R., O'Rourke K.I., Hoover E.A., Oral transmission and early lymphoid tropism of chronic wasting disease $\mathrm{PrP}^{\mathrm{res}}$ in mule deer fawns (Odocoileus hemionus), J. Gen. Virol. (1999) 80:2757-2764.

[77] Sigurdson C.J., Spraker T.R., Miller M.W., Oesch B., Hoover E.A., PrPCWD in the myenteric plexus, vagosympathetic trunk and endocrine glands of deer with chronic wasting disease, J. Gen. Virol. (2001) 82:2327-2334.

[78] Sigurdson C.J., Manco G., Schwarz P., Liberski P., Hoover E.A., Hornemann S., et al., Strain fidelity of chronic wasting disease upon murine adaptation, J. Virol. (2006) 80:12303-12311.

[79] Sigurdson C.J., Nilsson K.P., Hornemann S., Manco G., Polymenidou M., Schwarz P., et al., Prion strain discrimination using luminescent conjugated polymers, Nat. Methods (2007) 4:1023-1030.

[80] Sigurdson C.J., Mathiason C.K., Perrott M.R., Eliason G.A., Spraker T.R., Glatzel M., et al., Experimental chronic wasting disease (CWD) in the ferret, J. Comp. Pathol. (2008) 138: 189-196.

[81] Spraker T.R., Balachandran A., Zhuang D., O'Rourke K.I., Variable patterns of distribution of $\mathrm{PrP}^{\mathrm{CWD}}$ in the obex and cranial lymphoid tissues of Rocky Mountain elk (Cervus elaphus nelsoni) with subclinical chronic wasting disease, Vet. Rec. (2004) 155:295-302.
[82] Spraker T.R., Gidlewski T.L., Balachandran A., VerCauteren K.C., Creekmore L., Munger R.D., Detection of PrPCWD in postmortem rectal lymphoid tissues in Rocky Mountain elk (Cervus elaphus nelsoni) infected with chronic wasting disease, J. Vet. Diagn. Invest. (2006) 18:553-557.

[83] Tallmon D.A., Draheim H.M., Mills L.S., Allendorf F.W., Insights into recently fragmented vole populations from combined genetic and demographic data, Mol. Ecol. (2002) 11:699-709.

[84] Tamgüney G., Giles K., Bouzamondo-Bernstein E., Bosque P.J., Miller M.W., Safar J., et al., Transmission of elk and deer prions to transgenic mice, J. Virol. (2006) 80:9104-9114.

[85] Trifilo M.J., Ying G., Teng C., Oldstone M.B., Chronic wasting disease of deer and elk in transgenic mice: oral transmission and pathobiology, Virology (2007) 365:136-143.

[86] Wadsworth J.D., Collinge J., Update on human prion disease, Biochim. Biophys. Acta (2007) 1772:598-609.

[87] Watts J.C., Balachandran A., Westaway D., The expanding universe of prion diseases, PLoS Pathog. (2006) 2:e26.

[88] Wild M.A., Spraker T.R., Sigurdson C.J., O'Rourke K.I., Miller M.W., Preclinical diagnosis of chronic wasting disease in captive mule deer (Odocoileus hemionus) and white-tailed deer (Odocoileus virginianus) using tonsillar biopsy, J. Gen. Virol. (2002) 83:2629-2634.

[89] Williams E.S., Young S., Chronic wasting disease of captive mule deer: a spongiform encephalopathy, J. Wildl. Dis. (1980) 16:89-98.

[90] Williams E.S., Young S., Spongiform encephalopathy of Rocky Mountain elk, J. Wildl. Dis. (1982) 18:465-471.

[91] Williams E.S., Young S., Spongiform encephalopathies in Cervidae, Rev. Sci. Tech. (1992) 11:551-567.

[92] Williams E.S., Miller M.W., Chronic wasting disease in deer and elk in North America, Rev. Sci. Tech. (2002) 21:305-316.

[93] Williams E.S., Chronic wasting disease, Vet. Pathol. (2005) 42:530-549.

[94] Wolfe L.L., Miller M.W., Williams E.S., Feasibility of "test-and-cull" for managing chronic wasting disease in urban mule deer, Wildl. Soc. Bull. (1994) 32:500-505

[95] Wolfe L.L., Spraker T.R., González L., Dagleish M.P., Sirochman T.M., Brown J.C., et al., PrPCWD in rectal lymphoid tissue of deer (Odocoileus spp.), J. Gen. Virol. (2007) 88:2078-2082.

[96] Xie Z., O’Rourke K.I., Dong Z., Jenny A.L., Langenberg J.A., Belay E.D., et al., Chronic wasting disease of elk and deer and Creutzfeldt-Jakob disease: comparative analysis of the scrapie prion protein, J. Biol. Chem. (2006) 281:4199-4206. 